\title{
Fault Diagnosis of LPRE Ground-testing Bed Based on PCA-SOM
}

\author{
Zhigang Feng \\ School of Automation, Shenyang Aerospace University, \\ Shenyang, Liaoning, China \\ fzg1023@yeah.net
}

\begin{abstract}
To effectively diagnose the deterministic faults of a LPRE ground-testing bed the fault diagnosis method based on PCA and SOM is proposed. The dimension reduction process of PCA not only reduces data size, but also reduces noise influence. It also intements a visualization of fault status identification and fault variable orientation bX SOM. Simulation and real fault data results indicate that the efficiency and identification ratio of PCA-SOM method are better than SOM method.
\end{abstract}

Keywords: ground-testing bed, fault diagnosis, principal component analysis (PCA), selforganizing map (SOM)

\section{Introduction}

Liquid propellant rocket engines (LPRE) are the heart of space vehicles and space transporting systems [1]. To ensure that design fequirements are fulfilled, a rocket engine should be tested on a ground-testing bed after production. The ground-testing bed is used to examine and test the controls and the other processes of the rocket engine. For example, the Space Shuttle main eng ne (SSME) is periodically tested by firing it on the ground using a testing bed located at the NASA Stennis Space Center. The testing bed provides a structure strong enough to hold a rocket engine in place as it is fired. It also serves as a fuel feed system that provides fuel and oxidizer to the engine. Typically, the fuel is liquid hydrogen and the oxidizer is liquid axygen. If there are any faults on the testing bed during groundtesting process, the testing bed improperly provides fuel and oxidizer for the rocket engine, making the rocket engine work abnormally. The rocket engine could even end up destroyed. Therefore, detecting anomalies in the ground-testing bed to decrease the bad effects on the rocket engine as caused by the faults is very important [2].

To detect anomalies and diagnose faults in the ground-testing bed, researchers have been focusing on finding a fault- detecting-and-diagnosis method since 2000. Temple proposes a testability analysis methodology that improves efficiency in terms of maintainability and a ailability of a system. A rocket engine testing bed is modeled and existing testing bed sensors are utilized as baseline for testability analysis [3]. Researchers at the NASA Ames Research Center explore a particular data-driven approach, based on normal detection algorithms from the machine learning community [4]. In 2005, researchers from the Harbin Institute of Technology concentrated on the study of the health monitoring system of an LPRE ground-testing bed [2]. Ning Zhu proposes a fault diagnosis approach based on a selforganizing map (SOM) to solve the fault diagnosis problem of an LPRE ground-testing bed [5]. This method is suitable for the diagnosis of the deterministic faults, which have been established the mechanism model or can generate enough reliable fault data. Simulation 
results show that SOM is a reliable and effective method for fault diagnosis and has good visualization property. However, the input data dimension for SOM is very large, making the training time of SOM very long. Moreover, some input data have little contribution to the fault diagnosis. Thus, extracting the main fault feature from the large input data to reduce input data dimension and to eliminate the bad influence of noise data is very necessary.

In this paper, the fault diagnosis method based on principal component analysis (PCA) and SOM is proposed. PCA is used to reduce data size and extract the fault feature from the sensor data. SOM is used to identify the fault type. Two types of ground-testing bed-simulated fault data are used to verify the proposed method. One type of fault data is generated by the mechanism model of the ground-testing bed. The other type of data is generated according to an expert's experience and the statistical model of the fault mode. SOM and PCA-SOM, in the aspect of fault diagnosis of ground-testing bed, are compared. Fault diagnosis reliability and fault diagnosis efficiency (time consumption property) are also studied. The comparison of PCA-SOM performance with a large sample and with a small sample is also studied. Finally, one group of fault data from an LPRE ground-testing bed is used to test the PCA-SOM method.

\section{Principle of Fault Diagnosis witt SOM}

SOM, developed by Kohonen [6], is a special km of artificial neural network that is based on competitive learning, where output neurons of the network compete among themselves. The purpose of SOM training is to compute optimal clustering of a collection of patterns in $\mathfrak{R}^{n}$. In SOM, neurons are typically arranged in a two-dimensional lattice called the feature map, as shown in Figure. 1. Each nearon receives inputs from the input layer (vectors in $\Re^{n}$ ) and from other neurons in the map During the learning process, the network performs clustering and the neurons are moved in the lattice to reflect cluster similarity through distances in the map. Each element in the SOM map is associated with one real vector (in $\Re^{n}$ ) that can be considered aprototype of the patterns in the cluster. For further details on SOM, we refer to $[7,8,9]$.

In the fault diagnosis of an LPRE ground-testing bed, SOM projects multidimensional ground-testing bed data into a two-dimensional map. A visualization of a SOM is used to cluster ground-testing bed data. The output map of the SOM is divided into several regions. Each region is represented by one fault mode. The fault mode of the testing data is determined according to the region where the labels belong to [5].

The steps of fauldragnosis using SOM are as follows:

(1) Training samples for every fault mode are selected and normalized.

(2) The structure of the SOM is determined and trained using all training samples. Fault mode names are then labeled on their respective winning neurons. The output map is then divided into several regions. Each region is represented by one fault mode.

(3) Testing data are mapped onto the trained SOM and their corresponding winning neurons are labeled.

(4) The fault mode of the testing data is then determined according to the region where their labels belong to. 


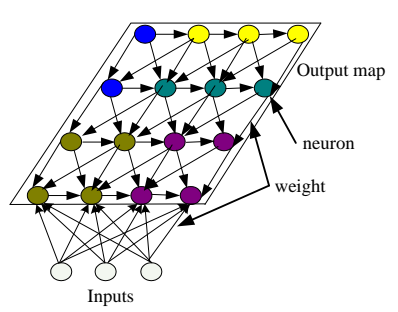

Figure 1. Architecture of SOM network

\section{Principle of Fault Diagnosis witt PCA-SOM}

PCA is a multivariable analysis method, which is also called matrix data analysis. Using variable transformation, correlated variables are changed into new uncorrelated variables, which are useful in data analysis. Thus, PCA is widely used in multi-dimensional analysis. The general method of PCA is described in References 10 and 11. PCA is now yidely used for lowering redundancy and for realizing reduction of data to erthance analysis efficiency. The method also reduces the dimensionality of high-variable space with mininal information loss $[12,13]$.

The dimension reduction process of PCA not only reduces data size, but also reduces noise influence. After this process, the SOM is trained. The output map with labels, which is called the U-matrix, is divided into several regions, with each region representing one fault. Finally, fault type is determined using variable U-rnatrix and load factor. A visualization of fault status identification and fault variable orientation is implemented.

A schematic of PCA-SOM for fault diagnosis is shown in Figure. 2.

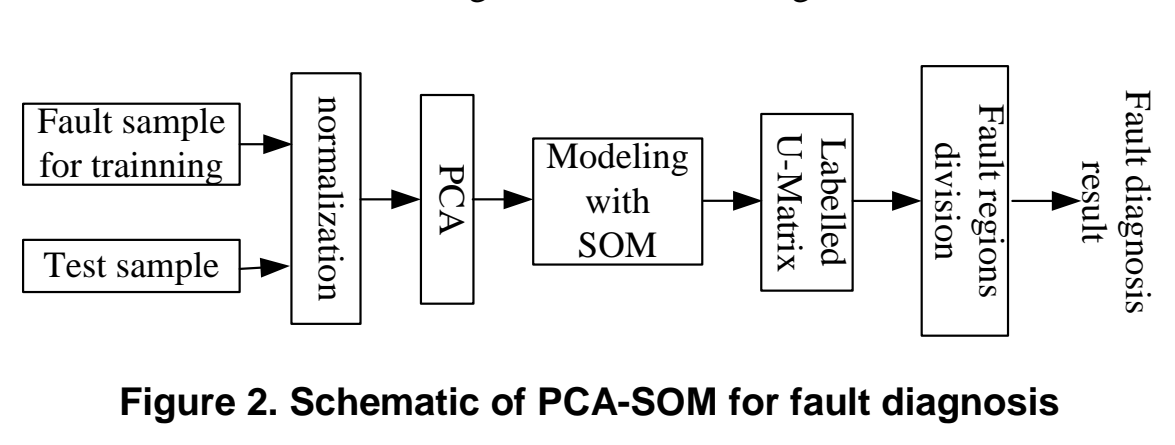

The steps of faultdiagn osis using PCA-SOM are as follows:

First, fault samples are normalized. Training samples for every fault mode are selected and normalized.

Second using PCA, dimension is reduced and noise is eliminated. PCA is then applied to the training samples, and selects the first $\mathrm{m}$ PCs as the new input data by calculating the contribution rate of each PC.

Third, using SOM, clustering follows. The structure of the SOM is determined and trained using new training samples composed of the first m PCs. The labeled U-Matrix is then generated by labeling the fault mode names on their respective winning neurons. The output map is divided into several regions according to the labeled U-Matrix, with each region represented by one fault mode. The testing data are then mapped onto the testing data on the trained SOM. Corresponding winning neurons are labeled. The fault mode of the testing data is determined according to the region where their labels belong to. 
Finally, the fault variable is removed. The fault variable is determined by analyzing the relationship between fault and PC using a variable U-matrix and by calculating the load factor of each variable to every PC.

\section{Experiment and Results}

To verify the proposed method, a comparison experiment for fault diagnosis reliability and fault diagnosis efficiency of SOM and PCA-SOM is conducted. A comparison experiment of PCA-SOM performance under a large sample and a small sample is also done. Two types of ground-testing-bed-simulated fault data are used. One type of fault data is generated by the mechanism model of the ground-testing bed. The other type of data is generated according to an expert's experience and the statistical model of the fault mode. Meanwhile, one group of fault data from an LPRE ground-testing bed is used to test the PCA-SOM method.

\subsection{Experiment and results, with fault data generated by the mechanism model}

Researchers from the Beijing Institute of Aerospace Testing Technology [14, 15] have established the mechanism model for four fault modes of the XXI ground-testing bed. The fault simulation architecture of the XX1 ground-testing bed liquid hydrogen system is shown in Figure 3.

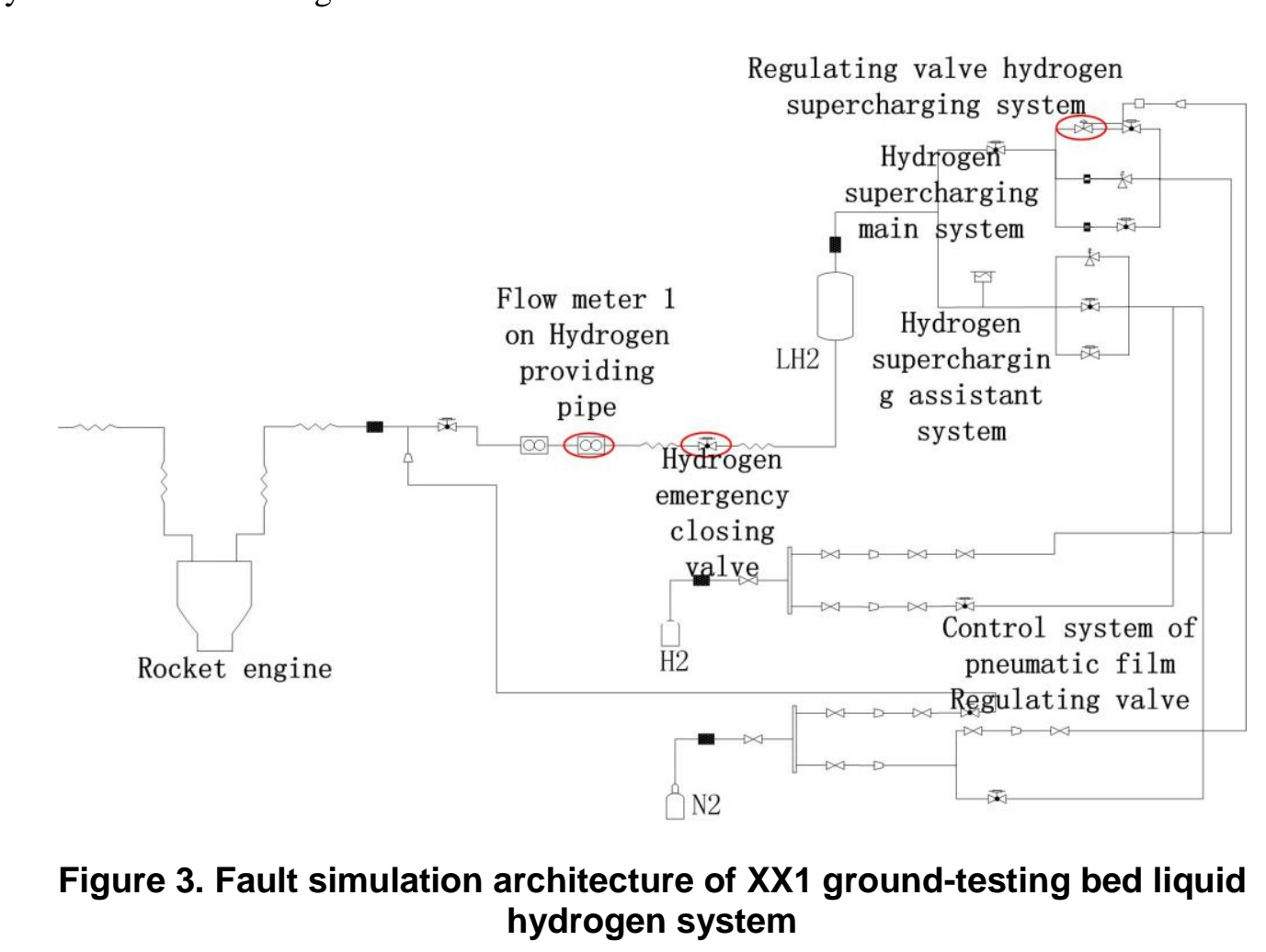

4.1.1. Fault diagnosis with PCA-SOM : According to the training and the testing procedures of PCA-SOM described in Section 3, 100 groups of simulation data are used to train PCA-SOM; the other 50 groups are used for testing. Table 2 shows the contribution rate of the principal components of the five fault types. For the five fault types, the cumulative 
contribution rate of the first two PCs are all greater than 0.95. Thus, the new training samples are composed of the first two PCs.

Table 1. Fault simulation data of a liquid hydrogen system

\begin{tabular}{llll}
\hline $\begin{array}{l}\text { Class } \\
\text { Num }\end{array}$ & Fault mode & Groups & $\begin{array}{c}\text { Fault } \\
\text { label }\end{array}$ \\
\hline 1 & Regulating valve opening abnormity of hydrogen-providing system & 150 & F1 \\
2 & Leakage of hydrogen emergency closing valve & 150 & F2 \\
3 & Hydrogen emergency closing valve opening abnormity & 150 & F3 \\
4 & Leakage of coupling flange before flow meter 1 on hydrogen-providing pipe & 150 & F4 \\
5 & Normal & 150 & Nor \\
\hline
\end{tabular}

Table 2. Contribution rate of principal component

\begin{tabular}{ccccccc}
\hline \multirow{2}{*}{ Fault type } & \multicolumn{5}{c}{ Contribution rate } & \\
\cline { 2 - 7 } & PC1 & PC2 & PC3 & PC4 & PC5 & PC1+PC2 \\
\hline F1 & 0.723 & 0.246 & 0.012 & 0.01 & 0.008 & 0.969 \\
F2 & 0.940 & 0.021 & 0.018 & 0.012 & 0.009 & 0.961 \\
F3 & 0.642 & 0.338 & 0.010 & 0.006 & 0.004 & 0.980 \\
F4 & 0.722 & 0.236 & 0.019 & 0.013 & 0.010 & 0.958 \\
\hline
\end{tabular}

Figures 4 and 5 show the labeled U-mat $1 \mathrm{x}$ map and the fault area map of the training samples, respectively. Figure 5 illustrates that the outpurmap of the SOM is divided into five regions, with each region representing one type of fault. Figure 6 shows the output map with labels of the testing samples. It indicates that some 2 samples are determined falsely as Nor. Table 3 shows the detailed faul diagnosis result of the testing samples with PCA-SOM, which indicates that the identification ratio for al fault modes is very high.

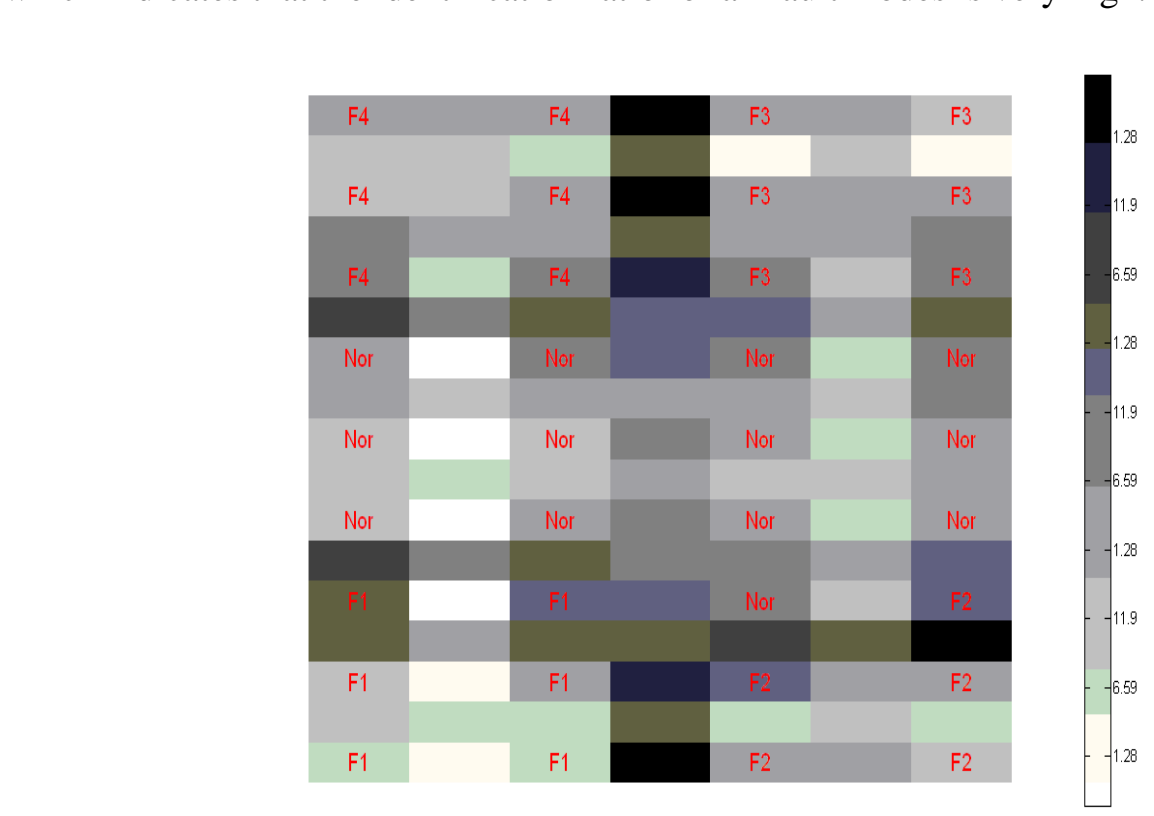

Figure 4. Labeled U-matrix map of training samples (PCA-SOM) 


\begin{tabular}{|c|c|c|c|}
\hline$F 4$ & $F 4$ & $F 3$ & $F 3$ \\
\hline$F 4$ & $F 4$ & $F 3$ & $F 3$ \\
\hline$F 4$ & $F 4$ & $F 3$ & $F 3$ \\
\hline Nor & Nor & Nor & Nor \\
\hline Nor & Nor & Nor & Nor \\
\hline Nor & Nor & Nor & Nor \\
\hline F1 & F1 & Nor & F2 \\
\hline F1 & F1 & F2 & F2 \\
\hline F1 & F1 & F2 & F2 \\
\hline
\end{tabular}

Figure 5. Fault area map of training samples (PCA-SOM)

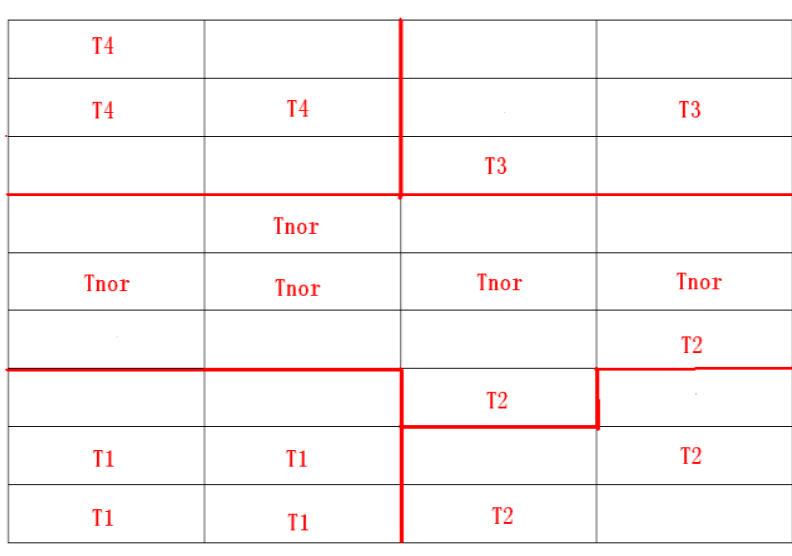

Figure 6 Output map with labels of the testing samples (PCA-SOM) 2

Table 3. Fault diagnosis results of testing samples with PCA-SOM

\begin{tabular}{lllllll}
\hline \multirow{2}{*}{ Testing data } & \multicolumn{7}{l}{ Fault diagnosis results } & \multirow{2}{*}{ Identification ratio/\% } \\
\cline { 2 - 5 } & F1 & F2 & F3 & F4 & Nor & \\
\hline F1 (50 groups) & 50 & 0 & 0 & 0 & 0 & $100 \%$ \\
F2 (50 groups) & 0 & 41 & 0 & 0 & 9 & $82 \%$ \\
F3 (50 groups) & 0 & 0 & 50 & 0 & 0 & $100 \%$ \\
F4 (50 groups) & 0 & 0 & 0 & 50 & 0 & $100 \%$ \\
Nor (50 groups) & 0 & 0 & 0 & 0 & 50 & $100 \%$ \\
\hline
\end{tabular}

4.1.2. Fault diagnosis with SOM: A detailed training and testing procedure of SOM is described in Reference 5 and Section 2. Figure 7 represents the labeled U-matrix map of training samples. Figure 8 shows the fault area map of training samples. Comparing Figures 5 and 8 , the fault region determined by PCA-SOM and SOM is different. Figure 9 presents the 
output map with labels of the testing samples. It indicates that some F2 samples are determined falsely as Nor and that some Nor samples are determined falsely as F2.

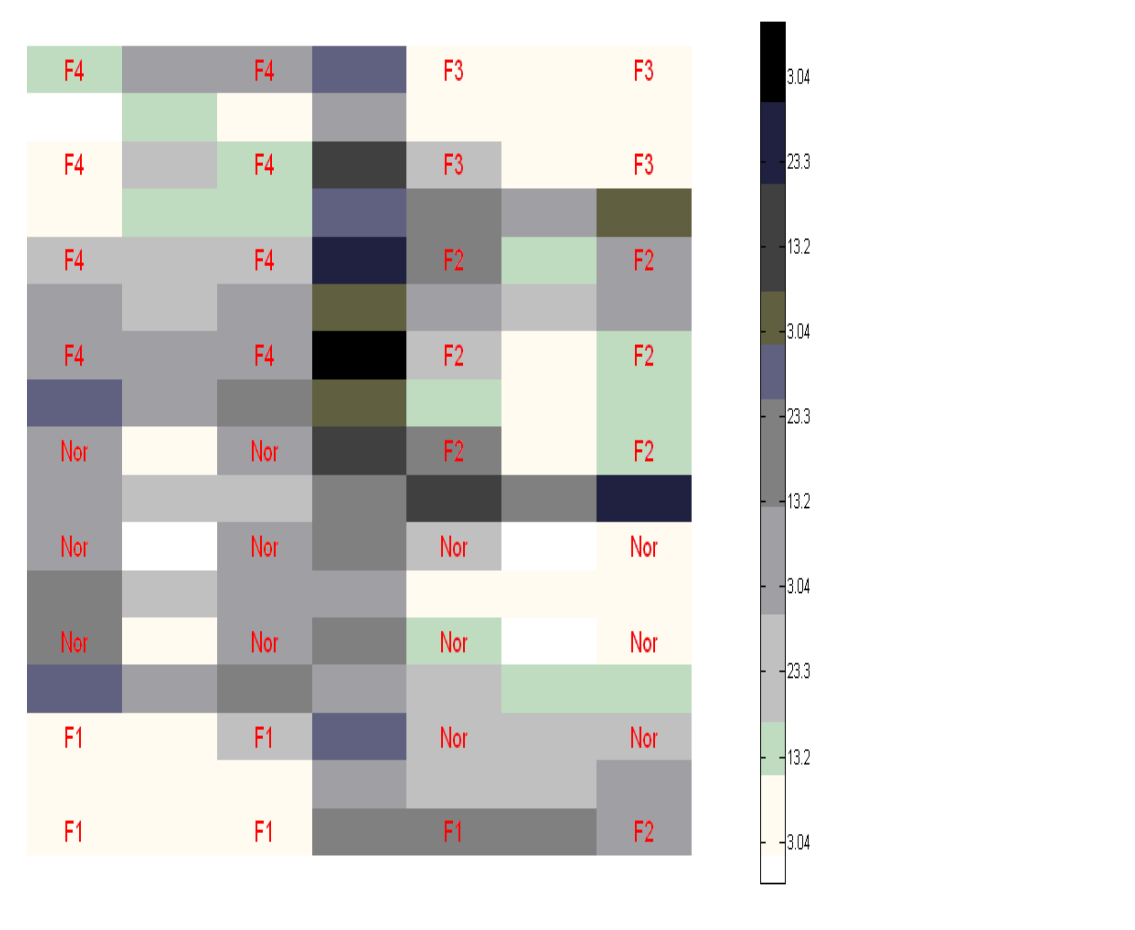

Figure 7. Labeled U matrix map of training samples (SOM)

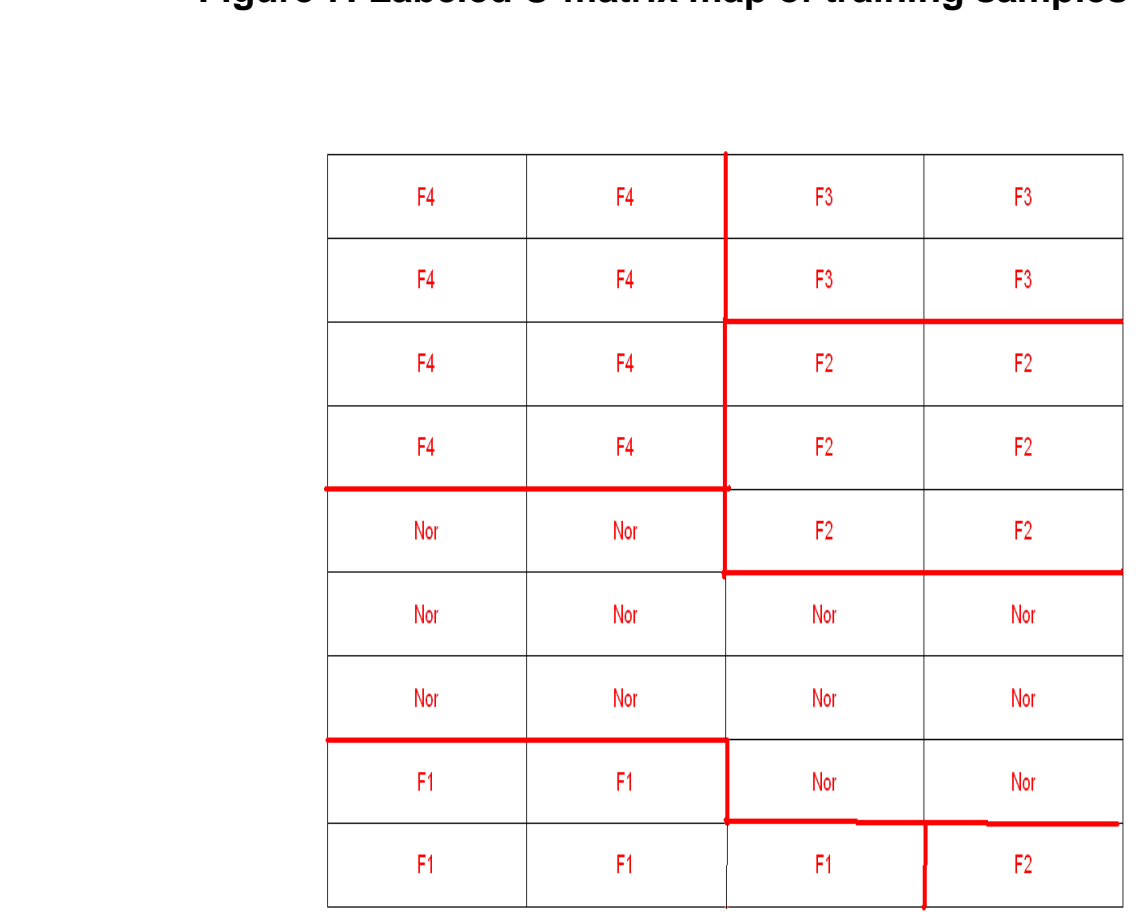

Figure 8. Fault area map of training samples (SOM) 


\begin{tabular}{|c|c|c|c|c|}
\hline T4 & & T3 & & T3 \\
\hline T4 & T4 & $\mathrm{T} 3$ & & \\
\hline \multicolumn{5}{|l|}{ T4 } \\
\hline & & T2 & & T2 \\
\hline & & T2 & & \\
\hline \multirow[t]{3}{*}{ Tnor } & Tnor & & T2 & Tnor \\
\hline & Tnor & Tnor & & \\
\hline & $\mathrm{T} 1$ & & & T2 \\
\hline $\mathrm{T} 1$ & $\mathrm{~T} 1$ & & & Tnor \\
\hline
\end{tabular}

Figure 9. Output map with labels of the testing samples (SOM)

Table 4 shows a detailed fault diagnosis result of the testing samples with SOM, which indicates that the identification ratio is lower thanthat of the PCA-SOM.

Table 4. Fault diagnosis results of testing samples with SOM

\begin{tabular}{ccccccc}
\hline \multirow{2}{*}{ Testing data } & \multicolumn{5}{c}{ Fault diagnosis results } & \multirow{2}{*}{ Identification ratio/\% } \\
\cline { 2 - 5 } & $\mathrm{F} 1$ & $\mathrm{~F}$ & $\mathrm{~F} 3$ & $\mathrm{~F} 4$ & Nor & \\
F1 (50 groups) & 50 & 0 & 0 & 0 & 0 & $100 \%$ \\
F2 (50 groups) & 0 & 40 & 0 & 0 & 10 & $80 \%$ \\
F3 (50 groups) & 0 & 0 & 50 & 0 & 0 & $100 \%$ \\
F4 (50 groups) & 0 & 0 & 0 & 50 & 0 & $100 \%$ \\
Nor (50 groups) & 0 & 8 & 0 & 0 & 42 & $84 \%$ \\
\hline
\end{tabular}

4.1.3. Comparison-results of PCA SOM and SOM: Table 5 shows the detailed results of the comparison between PCA-SOM and SOM, including identification ratio and time consumed. Both fault diagnosis reliability and fault diagnosis efficiency of PCA-SOM are better than those of SOM. Through PCA, data dimensions of the input data are reduced, so the training time of PCA-SOM is less than that of SOM. Meanwhile, noise in the input data is eliminated, so the identification ratio of PCA-SOM is higher than that of SOM.

Table 5. Comparison results between PCA-SOM and SOM

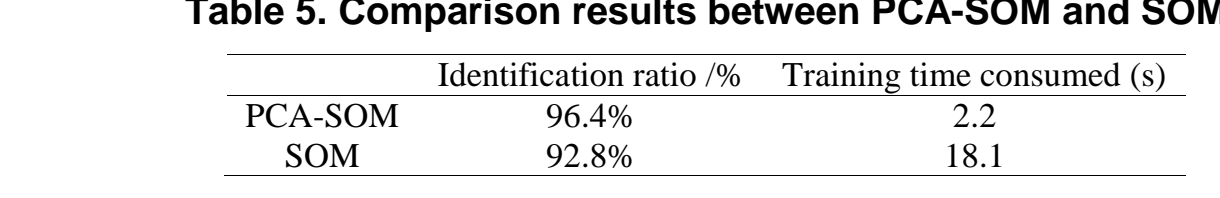

\subsection{Experiment and results, with fault data generated by statistical model}

This part describes the comparison results between PCA-SOM performance under a large sample and a small sample using fault data generated by statistical model. For the fault mode, which has not established the mechanism model, the fault data can be generated according to the fault mode analysis results and the statistical model. Figure 10 shows the fault data generation software of the statistical model. Fifteen fault modes of the liquid oxygen system are studied. Table 6 shows details of fault simulation data of the liquid oxygen system. 


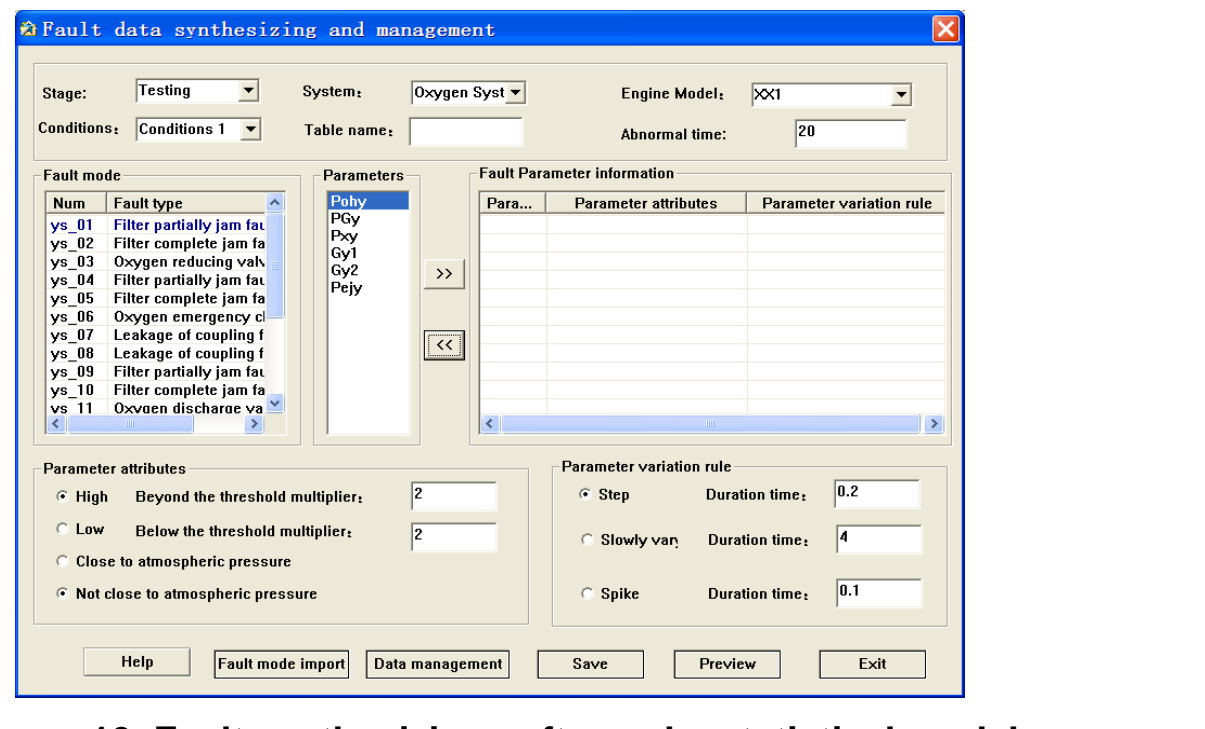

Figure 10. Fault synthesizing software by statistical model

Table 6. Fault simulation data of the liquid oxygen system

\begin{tabular}{|c|c|c|c|}
\hline $\begin{array}{l}\text { Class } \\
\text { Num }\end{array}$ & Fault mode & Groups & $\begin{array}{l}\text { Fault } \\
\text { label }\end{array}$ \\
\hline 1 & Filter partially blocked fault after the nitrogen source & 200 & F1 \\
\hline 2 & Filter completely blocked faut after the nitrogen source & 200 & $\mathrm{~F} 2$ \\
\hline 3 & Oxygen-reducing valye fault & 200 & F3 \\
\hline 4 & Filter partially blocked fault aboye oxygen tank & 200 & $\mathrm{~F} 4$ \\
\hline 5 & Filter completely blocked fault above oxygen tank & 200 & F5 \\
\hline 6 & mergency closing valve opening abnormity & 200 & F6 \\
\hline 7 & efore flow meter 1 on oxygen-providing pipe & 200 & F7 \\
\hline 8 & g flange before flow meter 2 on oxygen-providing pipe & 200 & F8 \\
\hline 9 & artially blocked fault on oxygen pipeline & 200 & F9 \\
\hline 10 & mpletely blocked fault on oxygen pipeline & 200 & F10 \\
\hline 11 & Irge valve closing abnormity & 200 & F11 \\
\hline 12 & Pressure measurement pipe blocked of oxygen & 200 & F12 \\
\hline 13 & ssure measurement pipe blocked of oxygen-reducing valve & 200 & F13 \\
\hline 11 & Pressure measurement pipe blocked of oxygen tank & 200 & F14 \\
\hline & Pressure measurement pipe blocked of oxygen pipeline & 200 & F15 \\
\hline & Normal & 200 & Nor \\
\hline
\end{tabular}

There are five parameters for every testing data, namely, pressure of oxygen-reducing valve (Pejy), pressure of oxygen tank (Pxy), pressure of oxygen pipeline (PGy), pressure of oxygen pump (Pohy), and flow of oxygen pipeline (Gy). A total of 200 groups of fault data are generated by this model.

4.2.1. Fault diagnosis of PCA-SOM with large samples: For the large sample testing process, 120 groups of data are used to train the PCA-SOM; the other 80 groups of data are 
used for testing. Figure 11 is the labeled U-matrix map of training samples. Figure 12 shows the fault area map of the training samples. Figure 12 also indicates that the output map of the SOM is divided into 17 regions, except for F14, which is divided into 2 regions, with each region representing one type of fault. Figure 13 presents the output map with labels of the testing samples using PCA-SOM. It indicates that some Nor samples are determined falsely as F12. Tables 7 and 8 show a detailed fault diagnosis result of the testing samples for PCASOM with large samples, which indicates that the identification ratio for all fault modes is very high.

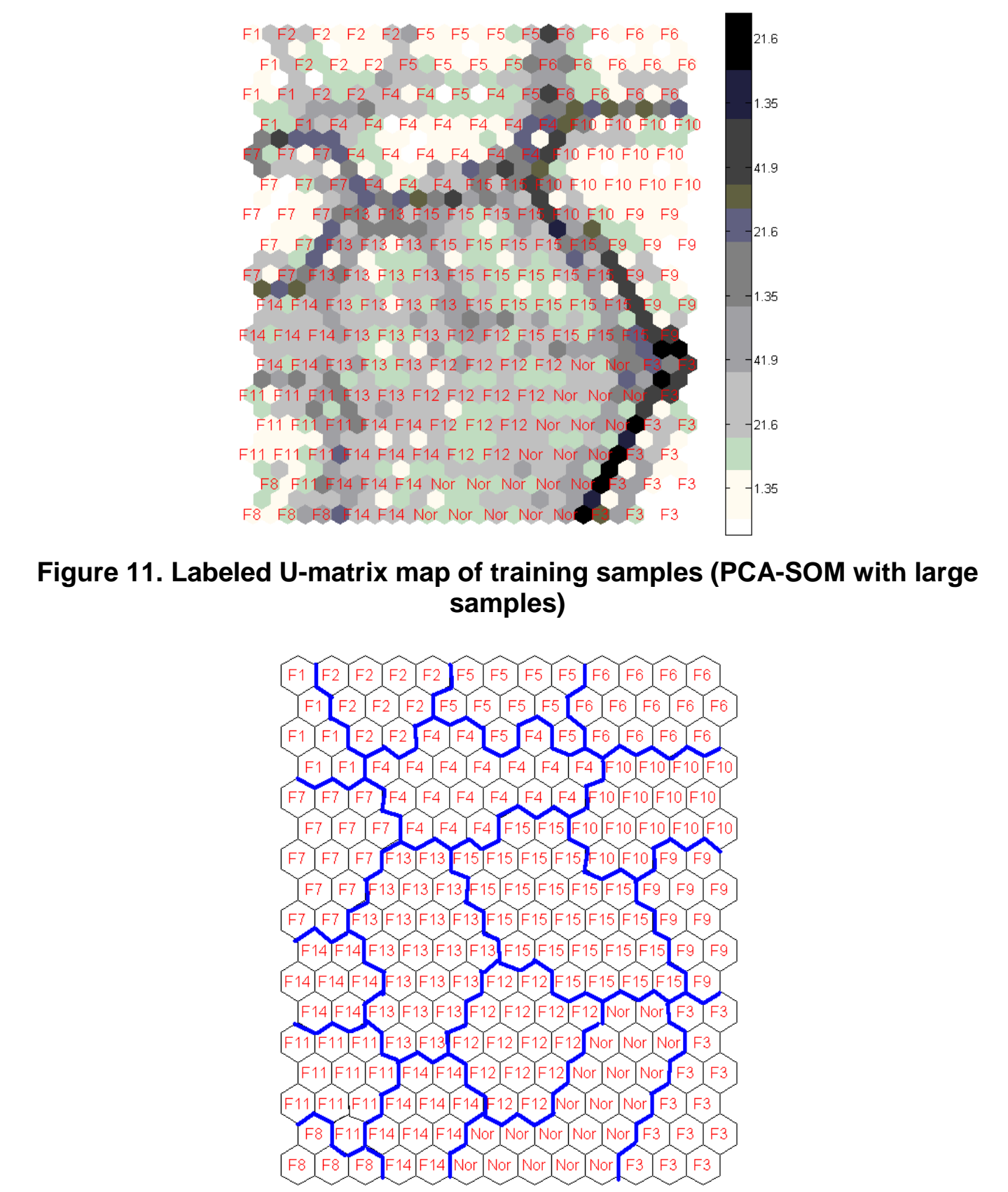

Figure 12. Fault area map of training samples (PCA-SOM with large samples) 


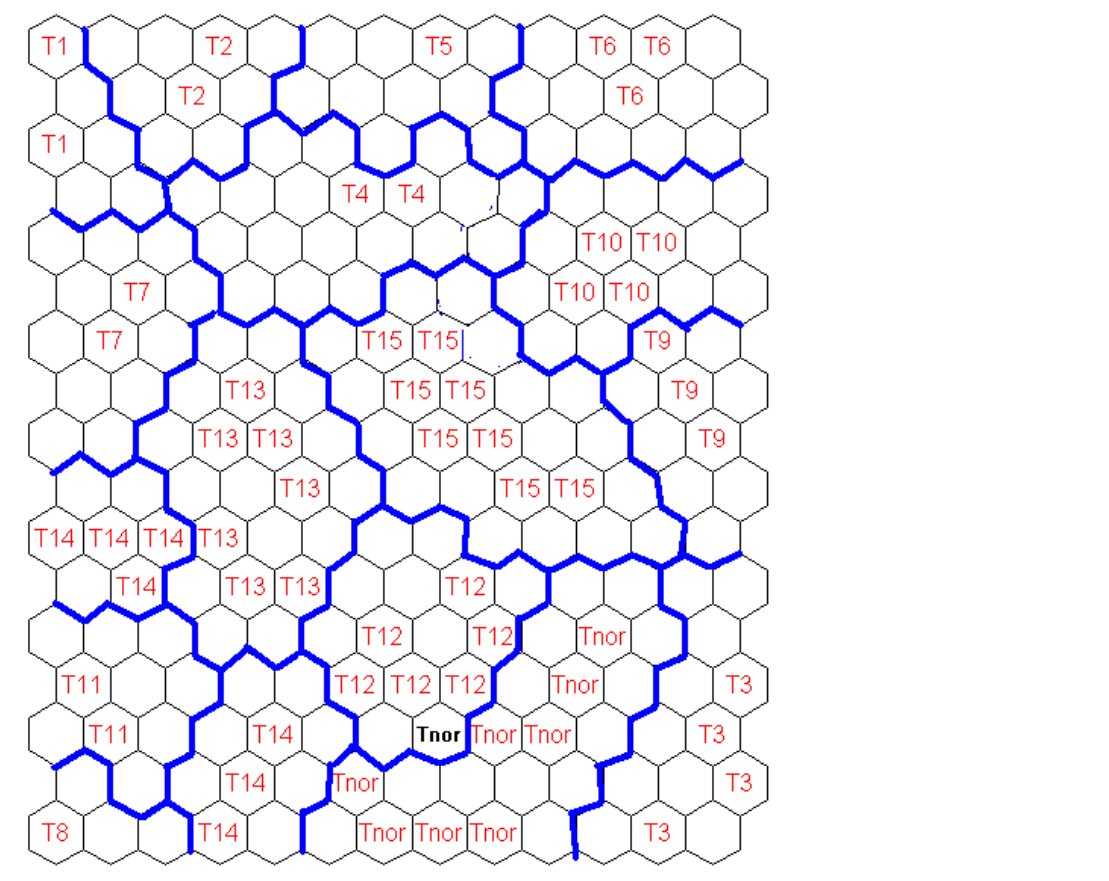

Figure 13. Output map with labels of the festing samples (PCA-SOM with large samples)

Table 7. Fault diagnosis results of the testing samples (PCA-SOM with large samples)

\begin{tabular}{|c|c|c|c|c|c|c|c|c|c|c|c|c|c|c|c|c|}
\hline \multirow{2}{*}{ Testing data- } & & & & & & & & & & \\
\hline & $\mathrm{F} 1$ & F2 & $\mathrm{F} 3$ & $F_{4}$ & F5 & $\mathrm{Fr}$ & F7 & $\mathrm{F} 8$ & F9 & F10 & F11 & F12 & F13 & F14 & F15 & Nor \\
\hline F1 & 80 & & & & 0 & 40 & 0 & 0 & 0 & 0 & 0 & 0 & 0 & 0 & 0 & 0 \\
\hline $\mathrm{F} 2$ & 0 & & & & 0 & & 0 & 0 & 0 & 0 & 0 & 0 & 0 & 0 & 0 & 0 \\
\hline F3 & & & & 0 & 0 & O & 0 & 0 & 0 & 0 & 0 & 0 & 0 & 0 & 0 & 0 \\
\hline F4 & & & 0 & & 20 & 0 & 0 & 0 & 0 & 0 & 0 & 0 & 0 & 0 & 0 & 0 \\
\hline F5 & & & 0 & & & 0 & 0 & 0 & 0 & 0 & 0 & 0 & 0 & 0 & 0 & 0 \\
\hline F6 & 0 & 0 & & & 0 & 81 & 0 & 0 & 0 & 0 & 0 & 0 & 0 & 0 & 0 & 0 \\
\hline F7 & 0 & 0 & & & 0 & 0 & 80 & 0 & 0 & 0 & 0 & 0 & 0 & 0 & 0 & 0 \\
\hline F8 & 0 & U & & 0 & 0 & 0 & 0 & 80 & 0 & 0 & 0 & 0 & 0 & 0 & 0 & 0 \\
\hline F9 & 0 & & 0 & 0 & 0 & 0 & 0 & 0 & 80 & 0 & 0 & 0 & 0 & 0 & 0 & 0 \\
\hline F10 & 0 & 0 & 0 & 0 & 0 & 0 & 0 & 0 & 0 & 80 & 0 & 0 & 0 & 0 & 0 & 0 \\
\hline F11 & $0=$ & 0 & 0 & 0 & 0 & 0 & 0 & 0 & 0 & 0 & 80 & 0 & 0 & 0 & 0 & 0 \\
\hline F12 & 0 & 0 & 0 & 0 & 0 & 0 & 0 & 0 & 0 & 0 & 0 & 80 & 0 & 0 & 0 & 0 \\
\hline & 0 & 0 & 0 & 0 & 0 & 0 & 0 & 0 & 0 & 0 & 0 & 0 & 80 & 0 & 0 & 0 \\
\hline & 0 & 0 & 0 & 0 & 0 & 0 & 0 & 0 & 0 & 0 & 0 & 0 & 0 & 80 & 0 & 0 \\
\hline & 0 & 0 & 0 & 0 & 0 & 0 & 0 & 0 & 0 & 0 & 0 & 0 & 0 & 0 & 80 & 0 \\
\hline Nor & 0 & 0 & 0 & 0 & 0 & 0 & 0 & 0 & 0 & 0 & 0 & 9 & 0 & 0 & 0 & 71 \\
\hline
\end{tabular}


Table 8. Fault recognition ratio of the testing samples (PCA-SOM with large samples)

\begin{tabular}{ccccccccc}
\hline $\begin{array}{c}\text { Testing } \\
\text { data }\end{array}$ & $\begin{array}{c}\text { Correct } \\
\text { Num }\end{array}$ & $\begin{array}{c}\text { Identifying } \\
\text { ratio }\end{array}$ & $\begin{array}{c}\text { Testing } \\
\text { data }\end{array}$ & $\begin{array}{c}\text { Correct } \\
\text { Num }\end{array}$ & $\begin{array}{c}\text { Identifying } \\
\text { ratio }\end{array}$ & $\begin{array}{c}\text { Testing } \\
\text { data }\end{array}$ & $\begin{array}{c}\text { Correct } \\
\text { Num }\end{array}$ & $\begin{array}{c}\text { Identifying } \\
\text { ratio }\end{array}$ \\
\hline F1(80) & 80 & $100 \%$ & F2(80) & 80 & $100 \%$ & F3(80) & 80 & $100 \%$ \\
F4(80) & 80 & $100 \%$ & F5(80) & 80 & $100 \%$ & F6 $(80)$ & 80 & $100 \%$ \\
F7(80) & 80 & $100 \%$ & F8(80) & 80 & $100 \%$ & F9(80) & 80 & $100 \%$ \\
F10(80) & 80 & $100 \%$ & F11(80) & 80 & $100 \%$ & F12(80) & 80 & $100 \%$ \\
F13(80) & 80 & $100 \%$ & F14(80) & 80 & $100 \%$ & F15(80) & 80 & $100 \%$ \\
Nor(80) & 71 & $88.75 \%$ & ---- & ---- & ---- & ---- & --- & ---- \\
\hline
\end{tabular}

4.2.2. Fault diagnosis of PCA-SOM with small samples: For the small sample testing process, 20 groups of data are used to train the PCA-SOM; the other 180 groups of data are used for testing. Figure 14 presents a labeled U-matrix map of training samples. Figure 15 shows the fault area map of the training samples. Figure 15 also shows that the onttput map of the SOM is divided into 16 regions, with each region representing one type of fault. Figure 16 represents the output map with labels of the testing samples using PCA-SOM It indicates that some Nor samples are determined falsely as F12 and F14, some F11 samples are determined falsely as F8, some F13 samples are determined falsely as F14 and F12, and some F10 samples are determined falsely as F9. Tables 9 and 10 show detailed fault diagnosis results of the testing samples for PCA-SOM with small samples, whichindicate that all F11 samples are determined falsely as F8. A total of $82.78 \%$ of the F10 samples are determined falsely as F9. The identification ratio of F13 decreased to $72.78 \%$, in which 48 samples are determined as F14, and one sample is determined as F12. The identification ratio of Nor decreased to $68.33 \%$, in which 26 samples are determined as F14, 31 samples are determined as F12, and 2 samples are determined as F10.

\begin{tabular}{|c|c|c|c|c|c|c|c|c|c|c|c|c|c|c|c|c|}
\hline \multirow{2}{*}{\multicolumn{17}{|c|}{$\begin{array}{l}\text { Fault Diagnosis Results } \\
\text { F7 F8 F9 F10 }\end{array}$}} \\
\hline & F1 & 12 & 73 & $\mathrm{~F} 4$ & F5 & F6 & F7 & F8 & F9 & F10 & F11 & F12 & F13 & F14 & F15 & Nor \\
\hline $\mathrm{F} 1$ & 180 & & 0 & 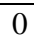 & & 0 & 0 & 0 & 0 & 0 & 0 & 0 & 0 & 0 & 0 & 0 \\
\hline F2 & 0 & 180 & 0 & 0 & 0 & 0 & 0 & 0 & 0 & 0 & 0 & 0 & 0 & 0 & 0 & 0 \\
\hline F3 & 0 & 0 & 180 & (6) & 0 & 0 & 0 & 0 & 0 & 0 & 0 & 0 & 0 & 0 & 0 & 0 \\
\hline F4 & 0 & 0 & & 18 & 0 & 0 & 0 & 0 & 0 & 0 & 0 & 0 & 0 & 0 & 0 & 0 \\
\hline F5 & 0 & 0 & & 0 & 180 & 0 & 0 & 0 & 0 & 0 & 0 & 0 & 0 & 0 & 0 & 0 \\
\hline F6 & 0 & 0 & 0 & 0 & 0 & 180 & 0 & 0 & 0 & 0 & 0 & 0 & 0 & 0 & 0 & 0 \\
\hline F7 & 0 & & 0 & 0 & 0 & 0 & 180 & 0 & 0 & 0 & 0 & 0 & 0 & 0 & 0 & 0 \\
\hline F8 & 0 & & 0 & 0 & 0 & 0 & 0 & 180 & 0 & 0 & 0 & 0 & 0 & 0 & 0 & 0 \\
\hline F9 & & 0 & 0 & 0 & 0 & 0 & 0 & 0 & 180 & 0 & 0 & 0 & 0 & 0 & 0 & 0 \\
\hline F10 & 0 & 0 & 0 & 0 & 0 & 0 & 0 & 0 & 149 & 31 & 0 & 0 & 0 & 0 & 0 & 0 \\
\hline & 0 & 0 & 0 & 0 & 0 & 0 & 0 & 180 & 0 & 0 & 0 & 0 & 0 & 0 & 0 & 0 \\
\hline F12 & 0 & 0 & 0 & 0 & 0 & 0 & 0 & 0 & 0 & 0 & 0 & 180 & 0 & 0 & 0 & 0 \\
\hline F13 & 0 & 0 & 0 & 0 & 0 & 0 & 0 & 0 & 0 & 0 & 0 & 1 & 131 & 48 & 0 & 0 \\
\hline F14 & 0 & 0 & 0 & 0 & 0 & 0 & 0 & 0 & 0 & 0 & 0 & 0 & 0 & 180 & 0 & 0 \\
\hline F15 & 0 & 0 & 0 & 0 & 0 & 0 & 0 & 0 & 0 & 0 & 0 & 0 & 0 & 0 & 180 & 0 \\
\hline Nor & 0 & 0 & 0 & 8 & 0 & 0 & 80 & 0 & 0 & 2 & 0 & 31 & 0 & 26 & 0 & 123 \\
\hline
\end{tabular}


Table 10. Fault recognition ratio of the testing samples (PCA-SOM with small samples)

\begin{tabular}{ccccccccc}
\hline $\begin{array}{c}\text { Testing } \\
\text { data }\end{array}$ & $\begin{array}{c}\text { Correct } \\
\text { Num }\end{array}$ & $\begin{array}{c}\text { Identifying } \\
\text { ratio }\end{array}$ & $\begin{array}{c}\text { Testing } \\
\text { data }\end{array}$ & $\begin{array}{c}\text { Correct } \\
\text { Num }\end{array}$ & $\begin{array}{c}\text { Identifying } \\
\text { ratio }\end{array}$ & $\begin{array}{c}\text { Testing } \\
\text { data }\end{array}$ & $\begin{array}{c}\text { Correct } \\
\text { Num }\end{array}$ & $\begin{array}{c}\text { Identifying } \\
\text { ratio }\end{array}$ \\
\hline F1(180) & 180 & $100 \%$ & F2(180) & 180 & $100 \%$ & F3(180) & 180 & $100 \%$ \\
F4(180) & 180 & $100 \%$ & F5(180) & 180 & $100 \%$ & F6 $(180)$ & 180 & $100 \%$ \\
F7(180) & 180 & $100 \%$ & F8(180) & 180 & $100 \%$ & F9(180) & 180 & $100 \%$ \\
F10(180) & 31 & $17.22 \%$ & F11(180) & 0 & $0 \%$ & F12(180) & 180 & $100 \%$ \\
F13(180) & 131 & $72.78 \%$ & F14(180) & 180 & $100 \%$ & F15(180) & 180 & $100 \%$ \\
Nor(180) & 123 & $68.33 \%$ & ---- & ---- & ---- & ---- & ---- & --- \\
\hline
\end{tabular}

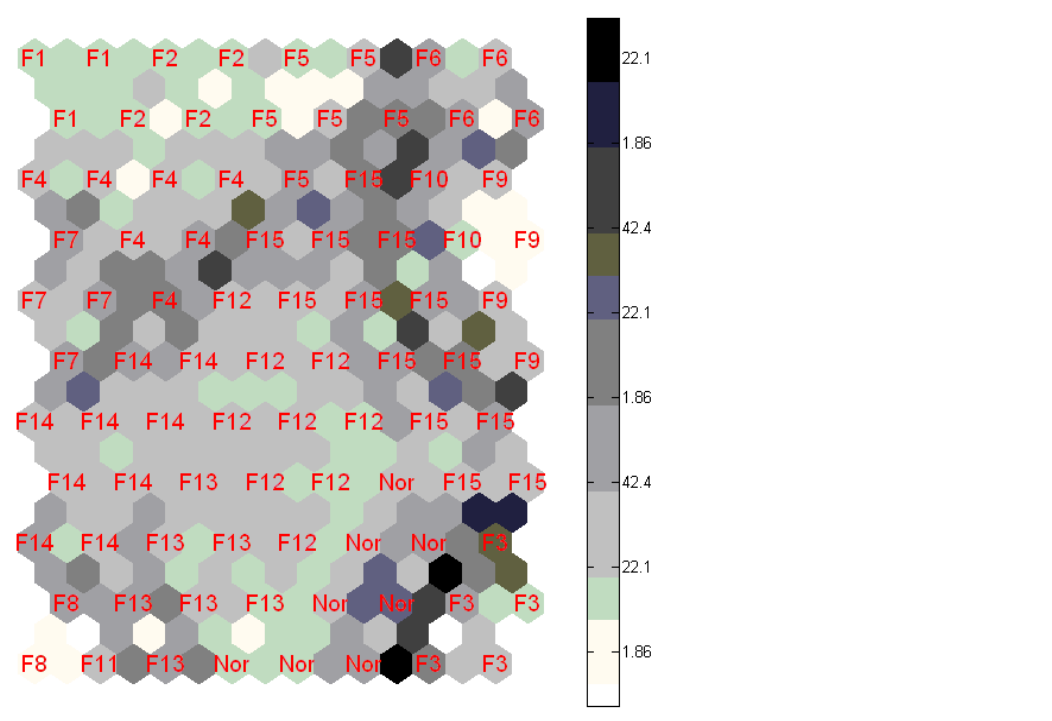

Figure 14. Labeled U-mat ix map of the training samples (PCA-SOM with small

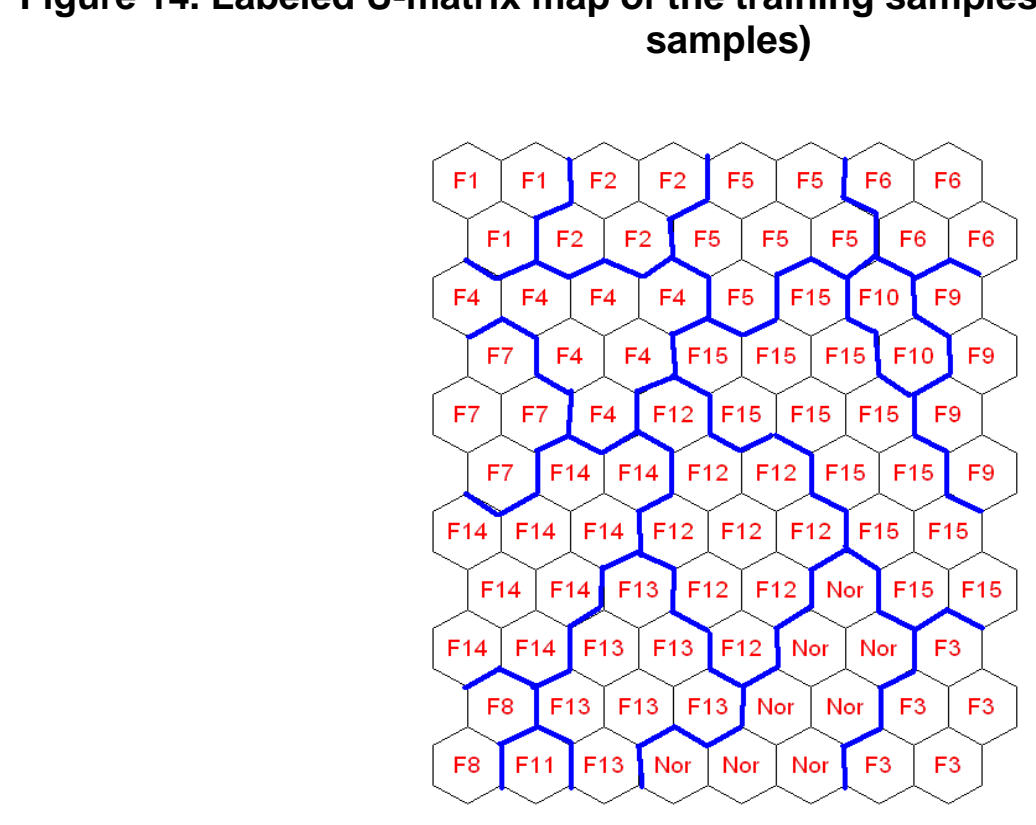

Figure 15. Fault area map of the training samples (PCA-SOM with small samples) 


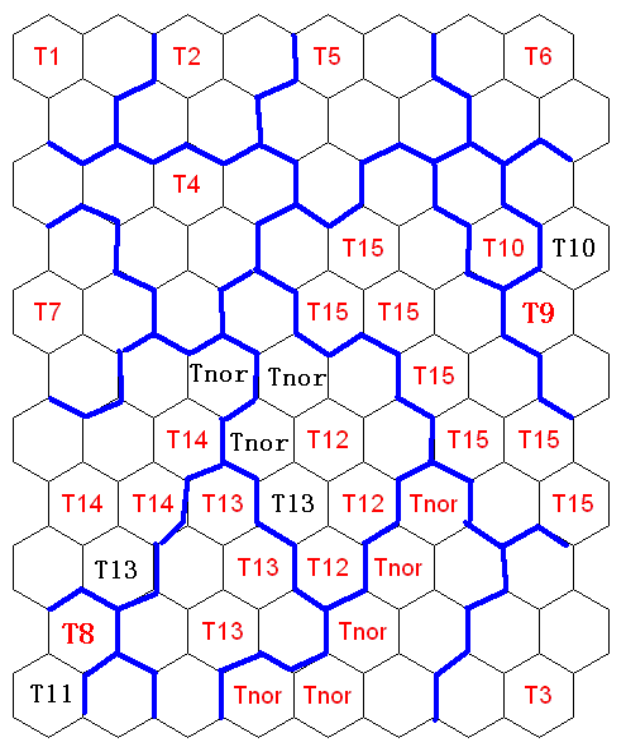

\section{Figure. 16. Output map with labels of the testing Samples (PCASOM with small samples)}

Under large training samples, PCA-SOM has a very bigh identification ratio. The identification ratio decreases apparently when the training samples decrease. Therefore, PCASOM is suitable for the fault mode that can goquire large Craining samples.

\subsection{Experiment and results with real fault data of XX1 LPRE ground-testing bed}

To verify the PCA-SOM method, one group of real fault data of XX1 LPRE ground-testing bed is used to test the performance. In this ground-testing process, a filter partially blocked fault above the oxygen ank occurs, resulting in the supercharging pressure not being able to fulfill the requirement. The engine is shyt down at about 70 seconds after firing. Curves of the four abnormal parameters are shown in Figures 17 to 20.

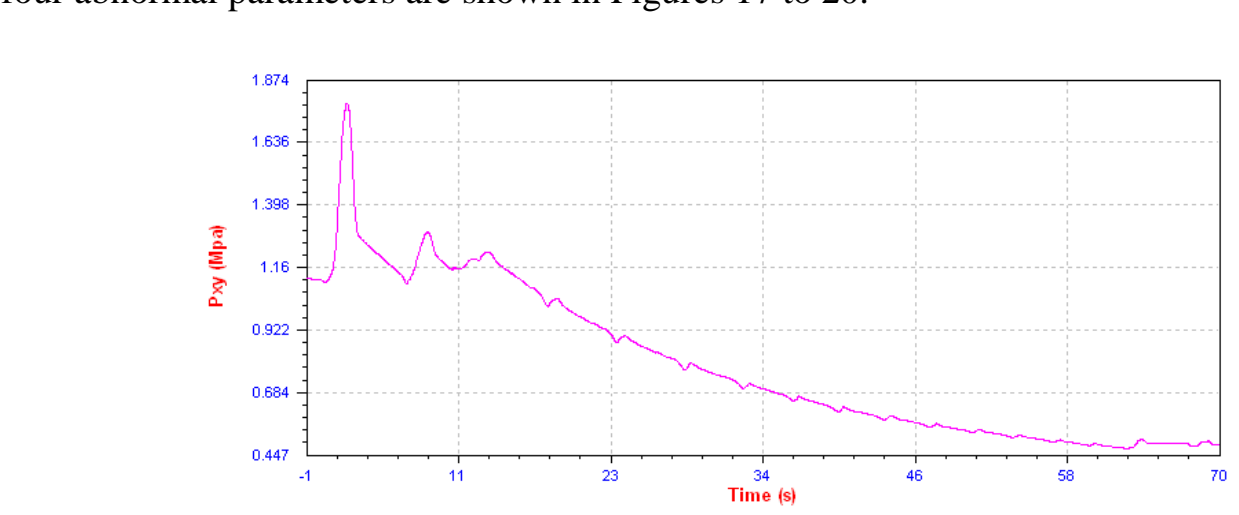

Figure 17. Curve of parameter Pxy 


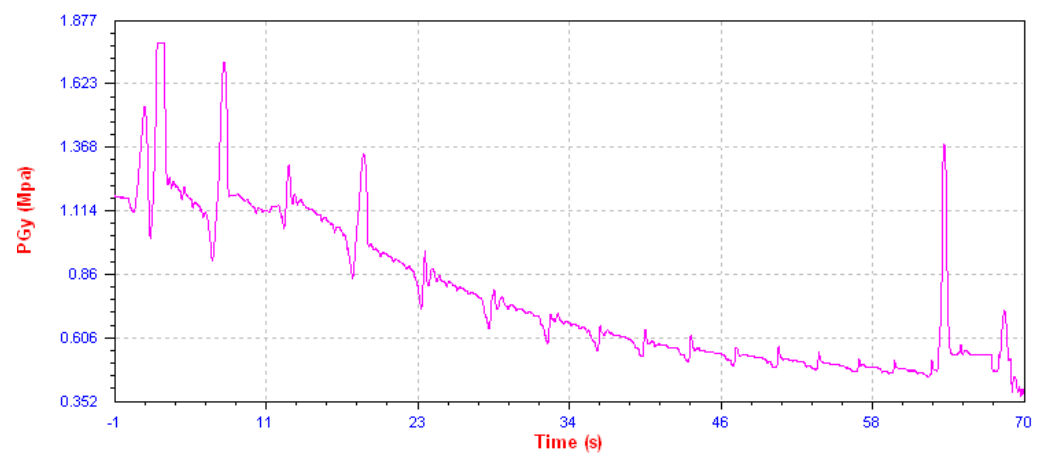

Figure 18. Curve of parameter PGy
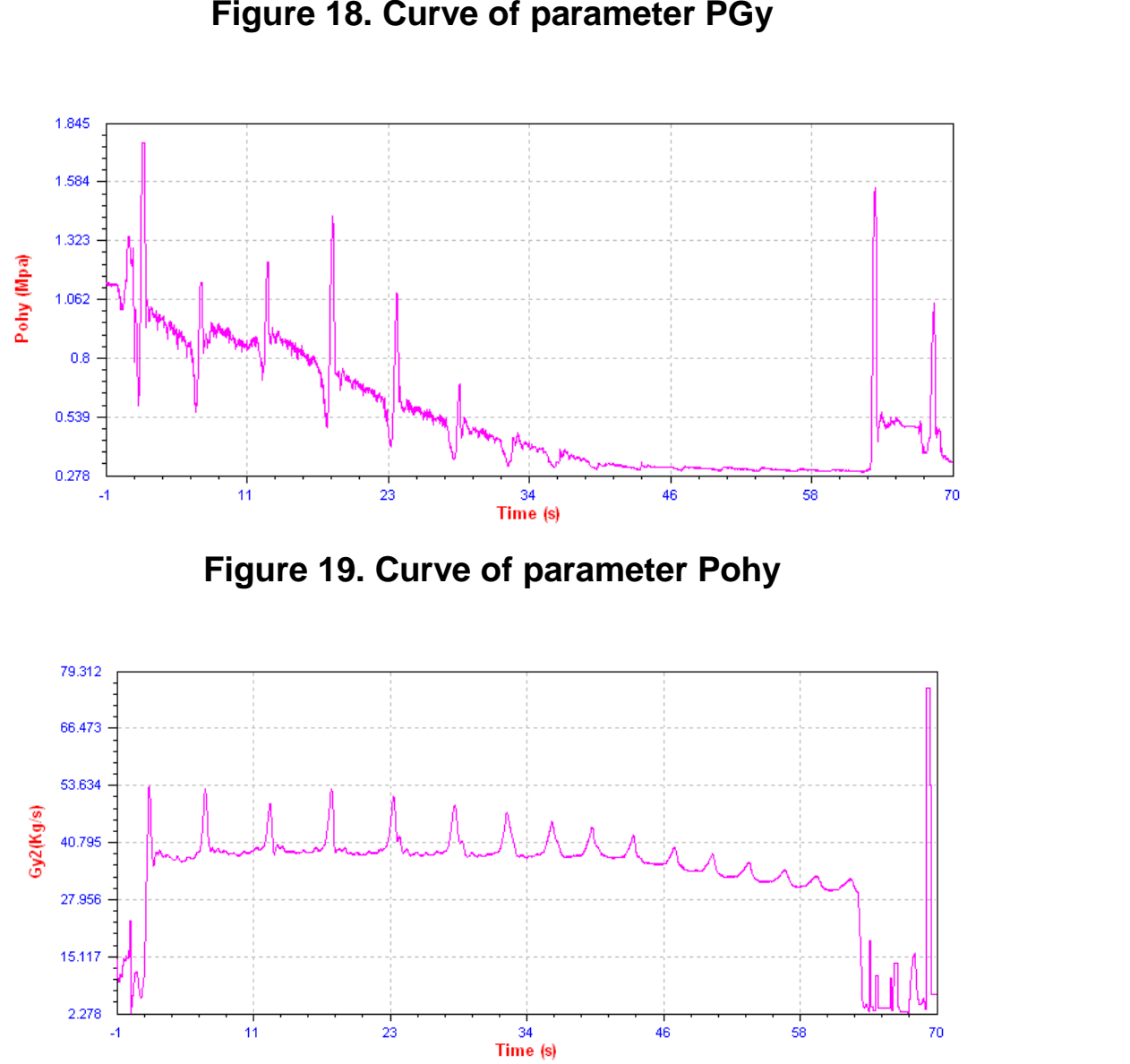

Figure 20. Curve of parameter Gy

Starting at approximately 14 seconds, the value of Pxy, Pohy, PGy, and Gy begins to decrease slowly. Thus, data from the 14th second to the 26th second are extracted to diagnose the fault type. The extracted data are normalized and processed by the PCA, and then inputted to the trained SOM with large samples. Figure 21 is the output map with labels of this testing data. The fault type diagnosed by PCA-SOM is F4, that is, filter partially blocked fault above oxygen tank, which is the correct fault diagnosis result. 


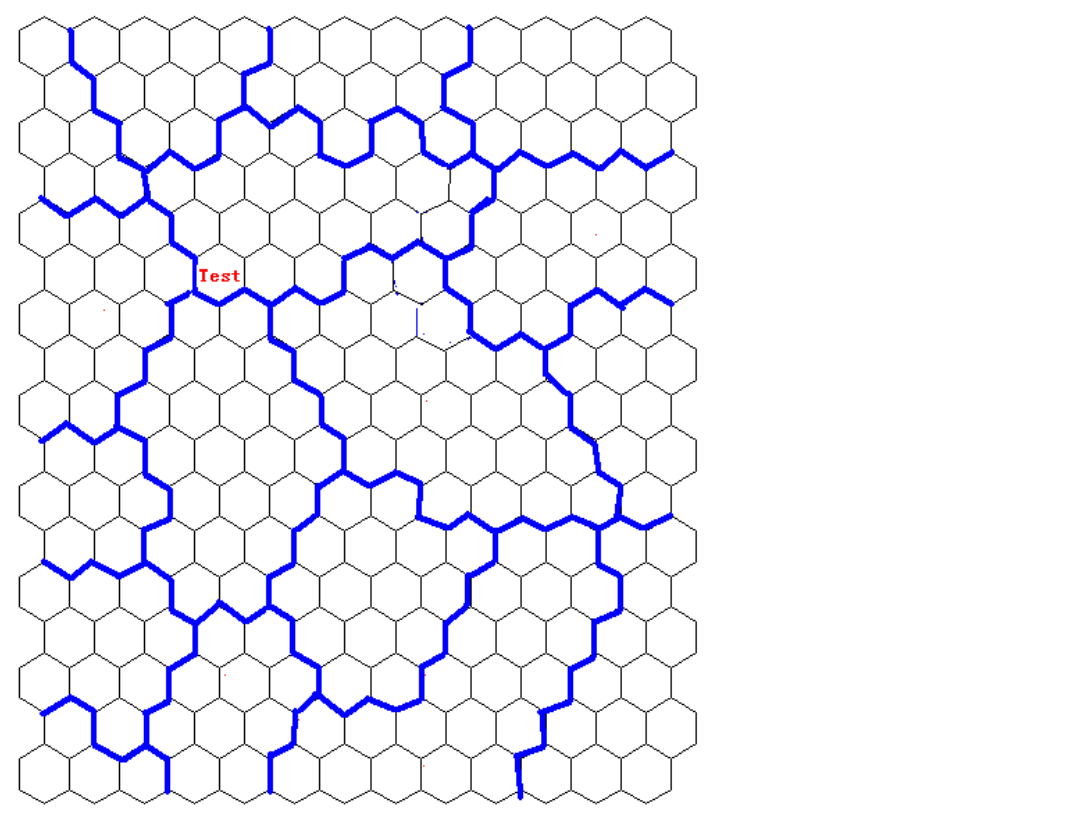

Figure 21. Output map with labels of the testing data (RCA-SOM with large samples)

\section{Conclusions}

Fault diagnosis of LPRE ground testing bed based on PCA and SOM is proposed. Comparison results of PCA-SOM and SOM using the fault data generated by the mechanism model indicate that both fault diagnosis reliability and fault diagnosis efficiency of PCASOM are better than those of SOM. Through PCA, data dimensions of input data are reduced, so the training time of PCA-SOM is less than that of SOM. In addition, through PCA, noise in the input data is eliminated, so the identification ratio of PCA-SOM is higher than that of SOM.

Comparison resalts of PCA-SQM under large samples and small samples using the fault data generated by the statistical model of fault mode indicate that PCA-SOM is suitable for the fault mode that can aequire training samples. Testing results of real fault data of XX1 LPRE ground-testing bed further verify that PCA-SOM is an efficient method in the diagnosis of the determinstic faults of an LPRE ground-testing bed.

\section{Acknowledgements}

The authors would like to thank the Education Department Foundation of Liaoning Province, China, for its funancial support. L2010427.

\section{References}

[1] J. Wu, "Liquid-propellant rocket engines health monitoring - a survey", Acta Astronautica, vol. 56, no. 3, (2005), pp. 347-356.

[2] Z. Feng and Q. Wang, "Research on Health Evaluation System of Liquid-propellant Rocket Engine Groundtesting bed Based on Fuzzy Theory", Acta Astronautica, vol. 61, no. 10, (2007), pp. 840-853.

[3] G. Temple, N. Jize and P. Wysocki, "Testability modeling and analysis of a rocket engine test stand", IEEE Aerospace Conference Proceedings, vol. 5, (2005), pp. 3874 - 3895.

[4] M. Schwabacher, "Machine learning for rocket propulsion health monitoring", SAE Transactions, vol. 114, no. 1, (2005), pp. 1580-1585. 
[5] N. Zhu, Z. Feng and Q. Wang, "Fault Diagnosis of Rocket Engine Ground Testing Bed with Self-organizing maps (SOMs)", Journal of Harbin Institute of Technology (New Series), vol. 16, no. 2, (2009), pp. 204-208.

[6] T. Kohonen, "Self-organizing maps", Springer Series in Information Sciences, (2001).

[7] J. Vesanto and E. Alhoniemi, "Clustering of the self-organizing map", IEEE Transactions on Neural Networks, vol. 11, no. 3, (2000), pp. 586-600.

[8] K. Benabdeslem and M. Lebbah, "Feature selection for self-organizing map", Proceedings of the International conference on Information Technology, (2007) October, pp. 45-50.

[9] B. Diri1 and S. Albayrak, "Visualization and Analysis of Classifiers Performance in Multi-class Medical data", Expert Systems with Applications, vol. 34, no. 1, (2008), pp. 628-634.

[10] I. T. Jolliffe, "Principal Component Analysis", New York, Berlin, Springer-Verlag, (1986).

[11] S. Ding, P. Zhang, E. Ding, et al. "On the Application of PCA Technique to Fault Diagnosis", Tsinghua Science and Technology, vol. 15, no. 2, (2010), pp. 138-144.

[12] Kondo, H. Ohno, and H. Fukuda, "Dimensionality Reduction for Metabolome Data using PCA, PLS, OPLS, and RFDA with Differential Penalties to Latent Variables", Chemo metrics and Intelligent Laboratory Systems, vol. 98, no. 2, (2009), pp. 136-142.

[13] G.-C. Luh and C.-Y. Lin, "PCA Based Immune Networks for Human Face Recognition", Applied Soft Computing, vol. 11, no. 2, (2011), pp. 1743-1752.

[14] Q. Zhang, Z. Zhang and X. Yang, "Fault Simulation and Analysis for the Fluid Systems of LPRE Test-Bed", Journal of Aerospace Power. vol. 21, no. 2, (2006), pp.403-409.

[15] C. Yang, Z. Zhenpeng and Q. Qian, "Numerical simulation for tank pressurization system of LRE test-bed". Journal of Aerospace Power. vol. 22, no. 1, (2007), pp. 96-101.

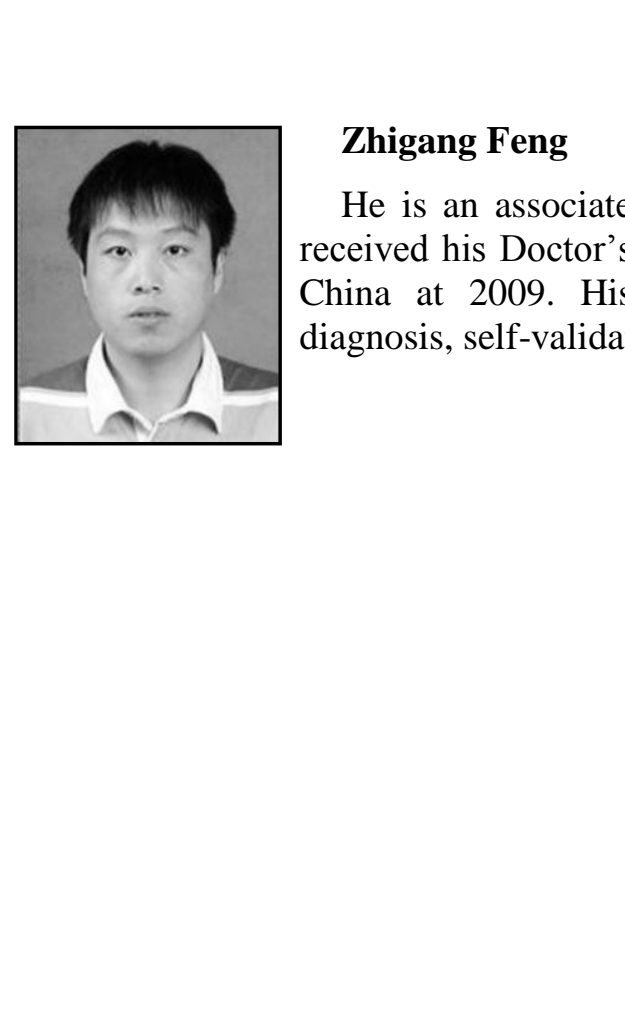

\section{Author}<smiles>c1ccc2ccccc2c1</smiles><smiles>[CH]1C[C@H]2CO[C@H]12</smiles>

Ate professor of Shenyang Aerospace University. He received his Doctor's Degree from Harbin Institute of Technology, P.R. China at 2009. His maln esearch direction includes system fault diagnosis, self-validating sensor and self-validating actuator. 
International Journal of Hybrid Information Technology

Vol.7, No.2 (2014)

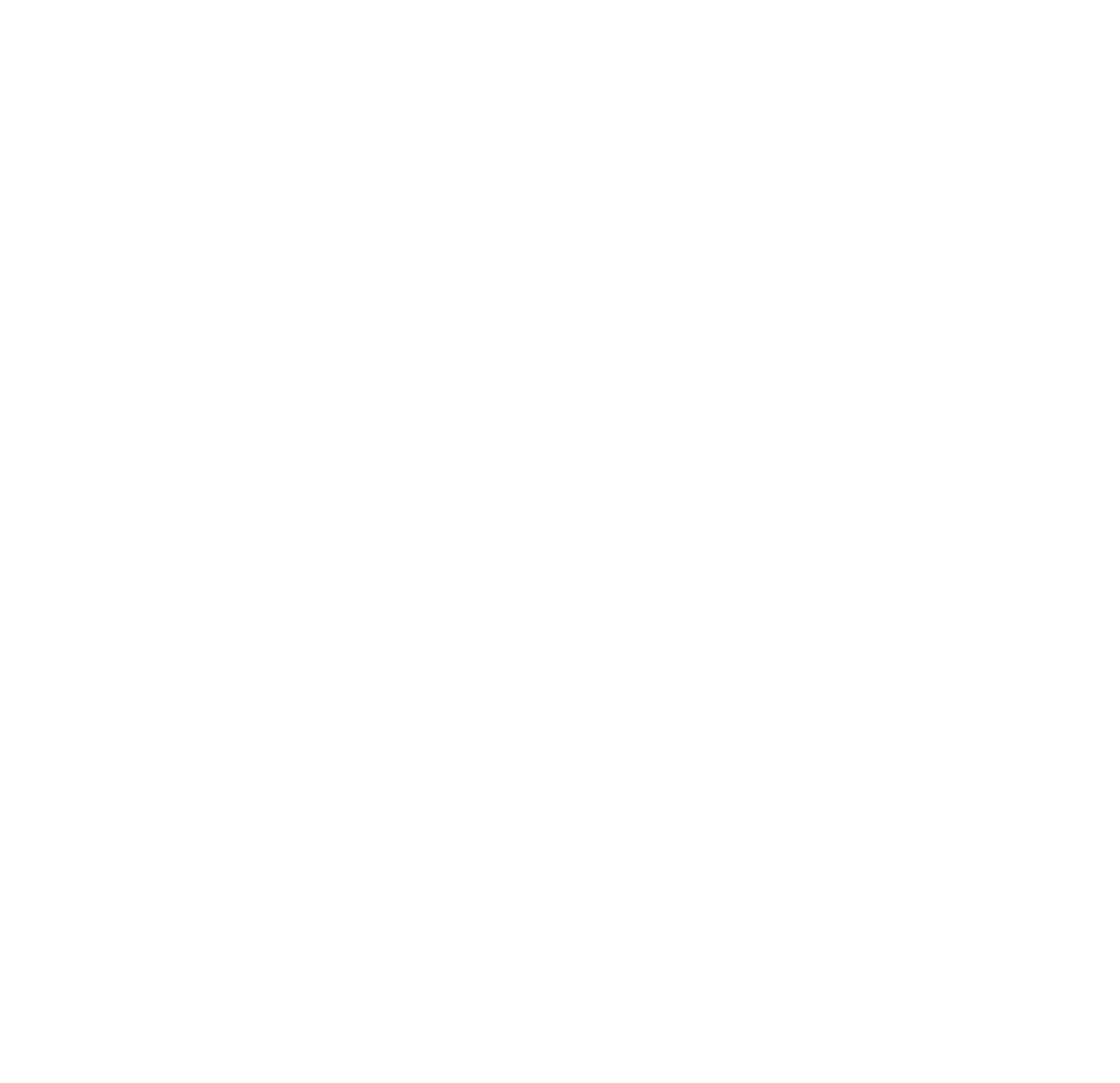

